\title{
EMOTION REGULATION AND SUBSTANCE USE
}

\section{Emna Bouguira, Uta Ouali, Yosra Zgueb, Abdelhafidh Ouertani, Fethi Nacef \\ Department of Psychiatry A. Razi Hospital La Manouba, Tunisia \\ Email adress: uta.ouali@gmail.com, bouguiraemna9@gmail.com}

Objectives : To study emotion regulation strategies among substance users.

Background and aims : Substance use and abuse is an increasing phenomenon in Tunisia, and addictions are now considered a serious public health problem. Although some national studies have evaluated substance use in younger adolescents, little is still known about its frequency among university students.

The aim of our study was to evaluate the rate of substance use and their relationship with emotion regulation strategies among university students.

Materials and methods: This is a cross-sectional study conducted between February and April 2017 at the Faculty of Legal Science and an Engineering School (ESPRIT) in Tunis/Tunisia. Students filled in the validated Tunisian-Arabic version of the Regulation of Emotions Questionnaire-2 (REQ-2T) as well as a questionnaire containing socio-demographic and clinical variables. Statistical analysis was performed using SPSS- 20.

Results : $\mathbf{3 8 4}$ students took part in the study. Mean age of study participants was 22 years. Alcohol was used by $35,7 \%$,cannabis by $11,45 \%$, and psychotropic drugs by $6,51 \%$ of the sample. The study showed a significant relationship between substance use and external dysfunctional emotion regulation strategies (e.g. physical or verbal violence). Inversely, there was a significant relationship between the absence of substance use and external functional emotion regulation strategies (e.g. seeking social support, physical activity).

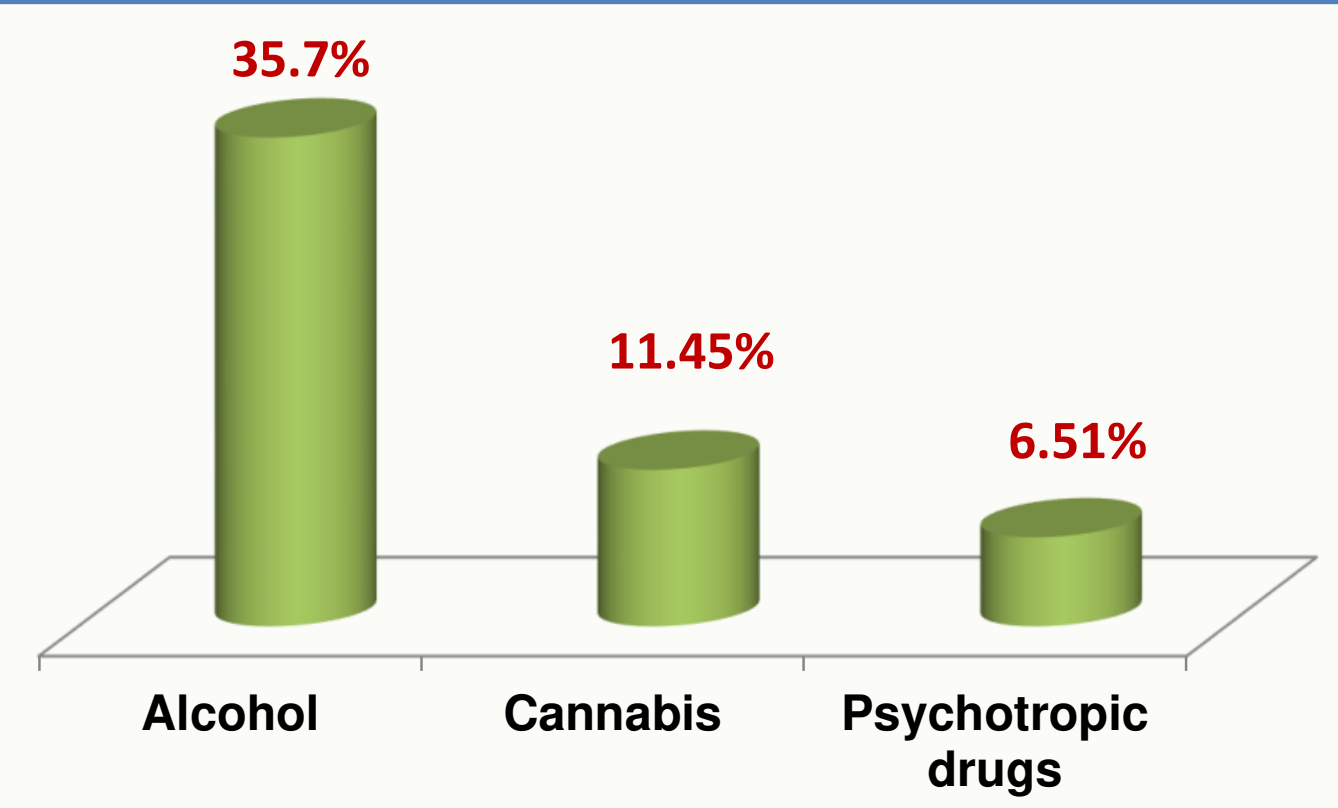

Chart 1: Substance use among university students
Discussion : Students reporting substance use were significantly more likely to use dysfunctional external emotion regulation strategies.

In 2003, Christo highlights the negative impact of addictive conduct on the individual [1]. Indeed, addictive behaviors can be considered as a means of calming negative emotions. The individual then seeks through these addictive mechanisms to inhibit and suppress his emotions [2]. In this sense, substane abuse can be seen as a strategy of dysfunctional emotion regulation strategies.

However, the relationship can also be interpreted in the opposite direction : the individual who has preferred to use dysfunctional emotion regulation strategies will be more likely to fall into the trap of addictions [3].

Conclusions : A high percentage of students in our sample use substances. Substance use was associated with dysfunctional emotion regulation strategies.

Therefore, prevention strategies and psychological support are necessary to address this problem.

The authors declare that there is no conflict of interest regarding the study.

Table I : Statistical relationships between REQ-2T subscales and substance use ( using the non-parametric Mann Whitney test)

\begin{tabular}{ccccc}
\hline & \multicolumn{4}{c}{ Substance use } \\
\hline & Yes & No & Significance \\
\hline $\begin{array}{c}\text { Internal dysfunctional } \\
\text { emotion regulation } \\
\text { strategies (F1) }\end{array}$ & Median & 12,00 & 11,00 & 0,342 \\
$\begin{array}{c}\text { Internal functional } \\
\text { emotion regulation } \\
\text { strategies (F2) }\end{array}$ & Median & 17,00 & 17,00 & 0,958 \\
$\begin{array}{c}\text { External dysfunctional } \\
\text { emotion regulation } \\
\text { strategies (F3) }\end{array}$ & Median & 7,00 & 6,00 & $0,000^{* *}$ \\
\hline $\begin{array}{c}\text { External functional } \\
\text { emotion regulation } \\
\text { strategies (F4) }\end{array}$ & Median & 10,00 & 12,00 & $0,000^{* *}$ \\
\hline
\end{tabular}

${ }^{* *}:$ The relationship is statistically significant at $p<0,005$

* : The relationship is statistically significant at $p<0,05$

1. Christo G, Jones SL, Haylett S, Stephenson GM, Lefever RMH, Lefever R. The shorter PROMIS questionnaire: further validation of a tool for simultaneous assessment of multiple addictive behaviours. Addict Behav. 2003;28(2):225-48.

Weiss BKW, Sullivan TP, Armeli S, Tennen H. Testing biderectional associations among emotion regulation strategies and substance use: a daily diary study. Addict. 2017;112(4):695-704.

. Sloan E, Hall K, Moulding R, Bryce S, Mildred H, Staiger PK. Emotion regulation as a transdiagnostic construct a cross anxiety, despression, substance, eating and borderline personality disorders: a systematic review. Clin Psychol Rev. 